\title{
Resilience, professionalism, and reflective thinking: The three-legged stool of health professional and teacher education students' fieldwork practice
}

\section{Resilienz, Professionalität und reflektierendes Denken: die drei Säulen für das Praktikum von Studierenden der Gesundheitsberufe und der Lehrerbildung}

Clifford J. Connell ${ }^{*}$, Ted Brown ${ }^{2}$, Alana Hewitt ${ }^{2}$, Averill Grieve ${ }^{3}$, Richard O'Donovan ${ }^{4}$, Daniel T. Malone ${ }^{5}$, Bella Ross ${ }^{3}$, Robert Cousland ${ }^{3}$, Louise Oliaro ${ }^{6}$, Mong-Lin $\mathrm{Yu}^{2}$

\author{
Monash University, Faculty of Medicine, Nursing and \\ Health Sciences, Monash Nursing and Midwifery, 3199 \\ Frankston, Australia. \\ * clifford.connell@monash.edu \\ ${ }^{2}$ Monash University, Faculty of Medicine, Nursing and $\mathrm{He}$ \\ alth Sciences, Department of Occupational Therapy, 3199 \\ Frankston, Australia. \\ ${ }^{3}$ Monash University, Faculty of Medicine, Nursing and \\ Health Sciences, Student Academic Support Unit (SASU), \\ 3145 Caulfield East, Australia. \\ ${ }^{4}$ Monash University, Faculty of Education, School of Cur- \\ riculum, Teaching and Inclusive Education, 3168 Clayton, \\ Australia. \\ ${ }^{5}$ Monash University, Faculty of Pharmacy and Pharmaceu- \\ tical Sciences, 3052 Parkville, Australia. \\ ${ }^{6}$ WeSupportU, 3192 Cheltenham, Australia
}

Received 13 April 2021, accepted 13 October 2021

\begin{abstract}
Background: Fieldwork is a core element of health professional and education student training that is often a professional registration and practice requirement. There are many personal, social, and professional factors that impact on students' fieldwork performance. The impact of professionalism, resilience, and reflective thinking on fieldwork performance is not well described in the literature.

Aim: To examine the relationship between health professional and teacher education university students' perceptions of professionalism, resilience, reflective thinking and their links to fieldwork performance.

Methods: Ten focus group interviews were conducted with university undergraduate or master's students across four disciplines: occupational therapy $(n=18)$, pharmacy $(n=6)$, social work $(n=38)$, and education $(n=16)$. Thematic analysis was used to identify codes and categories in focus group transcripts. Commonalities of ideas and constructs were identified and interpreted to create meaningful themes.

Results: Six themes were identified. Fieldwork placement created real-world opportunities for developing technical and nontechnical skills, professional acclimatization, psychosocial traits, and behaviors for coping with the transition from student to proto-professional. However, these outcomes had consequences related to bridging the gap between university course theory and the reality of the workplace, adapting to cultural differences and local practice as well as seeking their own resources, supports, and learning.

Conclusion: Despite the personal, professional, and practical challenges of fieldwork, students independently establish mental models of professionalism, resilience, and reflective thinking, which support their fieldwork performance. However, developing these mental models should be underpinned by theory, and coordinated university and industry supports should be provided to augment this process.
\end{abstract}

\footnotetext{
Abstract

Einleitung: Blockpraktika bilden ein Kernelement in der Ausbildung von Studierenden der Pädagogik und des Gesundheitswesens und sind oft eine Voraussetzung für den beruflichen Werdegang. Persönliche, soziale und professionelle Faktoren wirken sich auf die Arbeitsleistung der Studierenden während des Praktikums aus. Zu diesen gehören Professionalität, Resilienz und reflektives Denken, deren Effekt auf die Praktikumsleistung bis heute nur wenig erforscht wurde.

Ziel: Ziel dieser Studie ist es, den Zusammenhang zwischen der Wahrnehmung von Professionalität, Resilienz und reflektivem Denken sowie deren Zusammenhang mit den im Praktikum erbrachten Leistungen von Studierenden des Gesundheitswesens und der Pädagogik zu untersuchen. Methode: Es wurden zehn Fokusgruppeninterviews mit Universitätsstudierenden im Bachelor- oder Master-Studium in vier Disziplinen durchgeführt: Ergotherapie $(n=18)$, Pharmazie $(n=6)$, Sozialarbeit $(n=38)$ und Pädagogik $(n=16)$. Mithilfe der thematischen Analyse wurden Codes und Kategorien in den Transkripten der Fokusgruppen identifiziert. Ähnliche Ideen und Konstrukte wurden identifiziert, interpretiert und zu aussagekräftigen Themen zusammengefasst.

Ergebnisse: Sechs Themen wurden identifiziert. Das Praktikum schuf reale Möglichkeiten für die Entwicklung technischer und nicht-technischer Fähigkeiten, für die berufliche Eingewöhnung sowie für die Entwickelung psychosozialer Eigenschaften und Verhaltensweisen zur Bewältigung des Übergangs vom Studium ins Berufsleben. Dies hatte Konsequenzen für die Überbrückung der Kluft zwischen theoretischer Universitätslehre und der Realität des Arbeitsplatzes; für die Anpassung an kulturelle Unterschiede und die lokalen Arbeitsweisen sowie für die Suche nach eigenen Ressourcen, Unterstützung und Lernen.
}

¿ Open Access. (c) 2021 ???? et al., published by Sciendo. (c) Br-Nc-ND This work is licensed under the Creative Commons AttributionNonCommercial-NoDerivatives 4.0 License. 
Fazit: Trotz der persönlichen, beruflichen und praktischen Herausforderungen der Blockpraktika entwickeln Studentinnen und Studenten eigenständige mentale Modelle der Professionalität, der Belastbarkeit und des reflektiven Denkens, welche ihre Leistung während der Arbeit im Praktikum unterstützen. Allerdings sollte die Entwicklung dieser Modelle in Zukunft durch theoretisches Vorwissen bestärkt werden. Weiter sollten Universitäten und Arbeitgeber zusammenarbeiten, um diesen Prozess zu fördern.

\section{Keywords}

Education - Professionalism - Resilience - Reflective thinking - Fieldwork - Placement

Keywords

Ausbildung - Professionalität - Resilienz - reflektiertes Denken - Feldarbeit - Praktikum

\section{INTRODUCTION}

Fieldwork (also known as practice education, placement, work-integrated learning, or industry internships) is a fundamental component of health professional and education student training (Bonello, 2016). For profession-based vocational undergraduate, graduateentry master's, and entry-to-practice clinical doctorate degrees, fieldwork often forms a mandatory requirement to obtain professional registration for practice (McAllister \& Nagarajan, 2015). Undergraduate fieldwork in these vocational disciplines provides opportunities for students to apply theoretical knowledge, practice psychomotor skills, begin to develop a professional identity, and acclimatize to the workforce. However, many personal, social, and professional factors impact on students' successful completion of such mandatory fieldwork placements. Professionalism, resilience, and reflective thinking are three areas of potential impact on the fieldwork performance of allied health and education students that have not been well described in the literature (Brown, Yu, Hewitt, \& Etherington, 2020).

Professionalism encompasses positive identifiable quantifiable qualities (e.g., altruism, integrity, ethical conduct), behaviors (e.g., accountability, punctuality, thoroughness), and attitudes (e.g., respect, selfregulation, non-judgment) that health-care and education professionals should demonstrate (Barnard, 2016). These core traits are demonstrated through the individual's commitment to and concordance with ethical practice, the quality of their interactions with clients, students, and colleagues, their reliability, and commitment to self-improvement (Arnold, 2002). Engendering these traits via undergraduate curricula has become a focus within health-care and teaching education, and is often mandated as an accreditation requirement (Larson, 2014; Medical Professionalism Project, 2002). The practical nature of supervised fieldwork makes it well suited to developing these professional traits, particularly with respect to resilience and reflective thinking (Brown, Yu, Hewitt, Isbel, et al., 2020).

Resilience is conceptualized as the ability to activate positive traits during stressful life events such as adversity, trauma, or tragedy, which prevent negative mental health outcomes and improves well-being (Russo, Murrough, Han, Charney, \& Nestler, 2012). Burnout among health-care and education practitioners (i.e., feelings of cynicism, early retirement, alcoholism, and suicidal ideation) has been linked to a lack of resilience building (Henrich et al., 2017), while fieldwork preparation and interventions that help to build resilience have shown positive outcomes for preparing resilient undergraduate students for the workforce (Lopez, Yobas, Chow, \& Shorey, 2018; Rakesh, Pier, \& Costales, 2017).

Reflective thinking, or reflective practice, is the ability to critique past events in order to develop strategies and uncover new learnings (Argyris, 1991; Dewey, 1997; Schön, 1938). Reflective thinking is integral to professional competence and is often incorporated into undergraduate, postgraduate, and in-service professional learning (Mann, Gordon, \& MacLeod, 2009). There is evidence that "honest" reflective practice does not come naturally, but it can be developed in simulated environments with careful design and integration into undergraduate curriculum and operationalized in fieldwork settings (Maloney, Tai, Lo, Molloy, \& Ilic, 2013).

Research indicates that working in the teaching and caring professions (including occupational therapy [OT], education, pharmacy, and social work [SW]) is rewarding, but emotionally demanding due to factors such as the nature of the work, inter-professional relationships, workplace environments, and their cultures (Brown, Yu, Hewitt, Isbel, et al., 2020; Fairbrother, Nicole, Blackford, Nagarajan, \& McAllister, 2016; Melman, Ashby, \& James, 2016; van Vuuren, Bodenstein, \& Nel, 2018; Venegas, Nkangu, Duffy, Fergusson, \& Spilg, 2019). These emotional demands are also experienced by students (both domestic and international) undertaking fieldwork placements (Joseph \& Rouse, 2017; Lalor, Yu, Brown, \& Thyer, 2019). Hence, developing resilience, reflective thinking, and professionalism throughout the educational and professional journey of a student practitioner is essential to ensure they can cope with such stressors. These traits are often identified by the following accreditation/registration bodies as key competencies for students to succeed in their chosen discipline: 


\begin{tabular}{|c|c|c|c|c|c|}
\hline & & $\begin{array}{l}\text { Length of } \\
\text { degree }\end{array}$ & Accreditation body & $\begin{array}{l}\text { Fieldwork hours } \\
\text { required }\end{array}$ & When fieldwork hours are completed \\
\hline \multirow[t]{2}{*}{$\begin{array}{l}\text { Occupational } \\
\text { therapy }\end{array}$} & Bachelor & 4 years & \multirow{2}{*}{$\begin{array}{l}\text { Occupational Therapy } \\
\text { Council of Australia \& } \\
\text { World Federation of } \\
\text { Occupational Therapists }\end{array}$} & 1000 & During each year of the course \\
\hline & Master & 2 years & & 1000 & $\begin{array}{l}\text { During the } 2 \text { years of the graduate-entry } \\
\text { master's course; students are required to } \\
\text { complete at least one placement that is a } \\
\text { minimum of } 8 \text { weeks in length }\end{array}$ \\
\hline \multirow[b]{2}{*}{ Pharmacy } & Bachelor & 4 years & $\begin{array}{c}\text { Australian Pharmacy } \\
\text { Council }\end{array}$ & $\begin{array}{l}\text { No minimum } \\
\text { requirement* }\end{array}$ & $\begin{array}{c}\text { During each year of the course. Two days } \\
\text { in year } 1,2 \text { weeks in year 2, } 4 \text { weeks in } \\
\text { year 3, and } 11 \text { weeks in year } 4\end{array}$ \\
\hline & Bachelor/Master & 5 years & $\begin{array}{c}\text { Australian Pharmacy } \\
\text { Council }\end{array}$ & 1824 & $\begin{array}{c}\text { During each year of the course. Two days } \\
\text { in year } 1,10 \text { days in year } 2,20 \text { days in year } \\
3,55 \text { days in year } 4 \text {, and } 228 \text { days ( } 1824 \mathrm{~h}) \\
\text { in year } 5\end{array}$ \\
\hline Social work & Master & 2 years & $\begin{array}{c}\text { Australian Association of } \\
\text { Social Workers }\end{array}$ & 1000 & During each year of the course \\
\hline \multirow{2}{*}{ Teaching } & Bachelor & 4 years & \multirow{2}{*}{$\begin{array}{l}\text { Australian Institute for } \\
\text { Teaching and School } \\
\text { Leadership }\end{array}$} & 80 days & During each year of the course \\
\hline & Master & 2 years & & 60 days & During each year of the course \\
\hline
\end{tabular}

*Australian Pharmacy Council requires that pharmacy programs must provide evidence that students have "demonstrated achievement of the degree performance outcomes to the specific level" and that this will require periods of work-integrated learning.

Occupational Therapy Board of Australia (Occupational Therapy Board of Australia, 2018), Australian Association of Social Workers (Australian Association of Social Workers, 2015), Australian Institute for Teaching and School Leadership (Australian Institute for Teaching and School Leadership, 2018), and Australian Pharmacy Council (Australian Pharmacy Council, 2020).

This study examines the relationship between health professional and teacher education university students' perceptions of professionalism, resilience, and reflective thinking and how students perceive these link to fieldwork performance. The findings will help inform the development of evidence-based pre-fieldwork placement curricula and assist in preparing both domestic and international students for successful industry placement.

\section{METHODS}

Focus groups were used to address the aims of the study. All participants were enrolled in undergraduate or master's degrees across four disciplines: OT, pharmacy, SW, and education. All courses had mandatory fieldwork components. Focus group data were collected to compare perspectives between the different disciplines and degrees in terms of students' experiences associated with professionalism, resilience, and reflective thinking as they related to fieldwork (Redmond \& Curtis, 2009).

\section{Study context}

The study was conducted between March and August 2019 at a metropolitan university in Victoria, Australia. The courses had varying requirements for fieldwork duration, context, and stage of course (see Table 1).

\section{Participants}

A purposive sample of participants $(N=78)$ was recruited from the OT, pharmacy, SW, and education disciplines at a large Australian university. OT students were in their third or fourth year of undergraduate studies or second-year master's program. Pharmacy students were in their third year of undergraduate studies. SW students were in their first- or second-year master's, and education students were in their second or third year of undergraduate studies or first-year master's degree.

University Human Research Ethics Committee approval was obtained in January 2019 (Project ID: 15205), and recruitment notices, including an explanatory statement, were posted on course learning management system fora. In some discipline areas, a blind copy recruitment email was also sent to potential student participants. Students indicated their interest in participating in the focus group via return email. Students meeting the inclusion criteria were provided with the focus group schedule details. 


\section{Data collection}

Participants took part in one of ten 1.5 hour focus groups, each with a maximum of 10 students from a single discipline. One researcher facilitated the focus group, while the second one recorded fieldnotes. The focus group proceedings were audio-recorded and transcribed verbatim. To minimize the impact of power relationships, the two investigators were not involved in providing any direct teaching or learning activities to the participants.

Prior to commencing the focus group, participants were given a brief outline of the aims of the study, a plain language participant information sheet, and a consent form. The focus groups were conducted in a university classroom with questions posed relating to professionalism, reflective thinking, resilience, and fieldwork (see Box 1). Each participant received an AU $\$ 25$ voucher as a token of thanks.

Introductory questions:
- What course are you each enrolled in at Monash University?
- $\quad$ How man year level of study are you currently enrolled in?
have you completed to date?
Are you enrolled as a domestic student or an international
student?
Students' views/perspectives on professionalism, reflective
thinking, and resilience during academic studies and during
practice education fieldwork/pre-service learning placements:
What is your definition of professionalism as a student in your
chosen discipline?
Do you think that professionalism is important in your chosen
discipline? Why?
What is your definition of reflective thinking as a student in
your chosen discipline?
Do you think that reflective thinking is important in your
chosen discipline? Why?
What is your definition of resilience as a student in your
chosen discipline?
Do you think that resilience is important in your chosen
discipline? Why?
Students' views/perspectives on field education/pre-service
learning:
What is your view of the role of field education/pre-service
Preparing students for success when completing practice
education fieldwork/pre-service learning placements:
- What resources related to professionalism, reflective thinking,
and resilience could be put in place to better prepare students
for success when completing field education/pre-service
learning placements?
education at university and field education/pre-service
learning placements you complete?
What are the benefits of completing field education/pre-
service learning placements?
What are the challenges related to completing field education/
What do you see as the relationship between professionalism,
reflective thinking, and resilience and completion of field
-
-

Box 1: Focus group questions.

\section{Data preparation}

Focus group recordings were transcribed into Microsoft Word $^{\mathrm{TM}}$ documents. The transcriptions were crosschecked with audio files prior to analysis and then imported into the web-based qualitative platform Dedoose $^{\text {TM }}$ for organization and analysis.

\section{Data analysis}

Participants were coded to denote their study discipline and year level (e.g., fourth-year SW, SW4; third-year pharmacy, PH3, etc.). Data were analyzed for themes iteratively by two of the authors (CC, AH). Audio recordings were first listened to, and then transcripts were read and reread while taking notes. Initial open coding was used, followed by focused line-by-line coding to refine existing codes and create categories. Forming themes and sub-themes involved collating the codes and categories and searching for commonality of ideas and constructs in the data. Themes and sub-theme descriptions were reviewed and refined through joint discussions and eventually assigned meaningful names with summaries and illustrative participant quotations (Braun \& Clarke, 2006).

\section{FINDINGS}

\section{Participant demographics}

The 78 participants spanned four disciplines: OT $(n=$ $18,23.1 \%$, two focus groups); pharmacy $(n=6,7.7 \%$, one focus group); education ( $n=16,20.5 \%$, three focus groups); and SW ( $n=38,48.7 \%$, four focus groups) (see Table 2).

Just over three-quarters $(n=60,76.9 \%)$ of the participants identified as female. The remaining participants identified as male $(n=15,19.2 \%)$ or preferred not to say $(n=3$, $3.8 \%$ ) (see Table 3). The mean age of the participants was 25.0 years $(\mathrm{SD}=4.9$, range $=23$ years) (see Table 4). All but one participant were enrolled in their course on a full-time basis $(n=77,98.7 \%)$. Majority $(n=51$, $65.4 \%$ ) of the participants were international students and $34.6 \%(n=27)$ were domestic students. Nearly half had entered their course with a school leaving certificate (n $=38,48.7 \%$ ), while less than a third entered their course with a bachelor's degree $(n=26,30.8 \%)$. The remaining participants, all of whom were Master of Social Work students, entered their course having completed a previous master's degree $(n=14,20.5 \%)$.

\section{Themes}

Six overall themes relating to participants' fieldwork 
Table 2: Demographics of focus group participants $(N=78)$.

\begin{tabular}{|c|c|c|c|}
\hline & & Frequency & Percent \\
\hline \multirow{4}{*}{ Discipline } & Occupational therapy & 18 & 23.1 \\
\hline & Pharmacy & 6 & 7.7 \\
\hline & Social work & 38 & 48.7 \\
\hline & Education & 16 & 20.5 \\
\hline \multirow{3}{*}{$\begin{array}{l}\text { Education level at the start of the } \\
\text { course }\end{array}$} & High school & 38 & 48.7 \\
\hline & Bachelor's & 24 & 30.8 \\
\hline & Master's & 16 & 20.5 \\
\hline \multirow{2}{*}{ Enrollment status } & Full time & 77 & 98.7 \\
\hline & Part time & 1 & 1.3 \\
\hline \multirow{2}{*}{ Enrollment type } & Domestic student & 27 & 34.6 \\
\hline & International student & 51 & 65.4 \\
\hline
\end{tabular}

Table 3: Demographics by discipline.

\begin{tabular}{c|c|c|c|c}
\hline Discipline & Gender & $\begin{array}{c}\text { Highest level of education } \\
\text { when started the current } \\
\text { course }\end{array}$ & Enrollment status & Enrollment type \\
\hline $\begin{array}{c}\text { Occupational therapy } \\
n=18\end{array}$ & $\begin{array}{c}13(72.2 \%) \text { female } \\
5(27.8 \%) \text { male } \\
\text { Two focus groups }\end{array}$ & $\begin{array}{c}17(94.4 \%) \text { high school } \\
1(5.6 \%) \text { bachelor's }\end{array}$ & $\begin{array}{c}17(94.4 \%) \text { full time } \\
1(5.6 \%) \text { part time }\end{array}$ & $\begin{array}{c}14(77.8 \%) \text { domestic } \\
\text { students } \\
4(22.2 \%) \text { international } \\
\text { students }\end{array}$ \\
\hline $\begin{array}{c}\text { Pharmacy } \\
n=6\end{array}$ & $\begin{array}{c}3(50 \%) \text { female } \\
\text { One focus group }\end{array}$ & $\begin{array}{c}5(80 \%) \text { male } \\
1(16.7 \%) \text { bachelor's }\end{array}$ & $6(100 \%)$ full time & 6 domestic students \\
\hline $\begin{array}{c}\text { Social work } \\
n=38\end{array}$ & $\begin{array}{c}30(79 \%) \text { female } \\
6(15.8 \%) \text { male }\end{array}$ & $\begin{array}{c}24(63.2 \%) \text { bachelor's } \\
14(36.8 \%) \text { master's }\end{array}$ & $38(100 \%)$ full time & $\begin{array}{c}38(100 \%) \text { international } \\
\text { students }\end{array}$ \\
$\begin{array}{c}\text { Four focus groups } \\
2(5.2 \%) \text { prefer not to say }\end{array}$ & $\begin{array}{c}14(87.5 \%) \text { female } \\
1(6.25 \%) \text { male }\end{array}$ & $16(100 \%)$ high school & $16(100 \%)$ full time & $\begin{array}{c}8(50 \%) \text { domestic students } \\
8(50 \%) \text { international } \\
\text { students }\end{array}$ \\
\hline $\begin{array}{c}\text { Education } \\
n=16\end{array}$ & $1(6.25 \%)$ prefer not to say
\end{tabular}

Table 4. Participants' age in years

\begin{tabular}{c|c|c}
\hline \multicolumn{4}{c}{} & Age (years) \\
\hline \multirow{4}{*}{ Occupational therapy } & Mean & 24.9 \\
\cline { 2 - 3 } & Std. deviation & 6.9 \\
\cline { 2 - 3 } & Range & 22.0 \\
\hline \multirow{4}{*}{ Pharmacy } & Mean & 20.8 \\
\cline { 2 - 3 } & Std. deviation & 1.2 \\
\cline { 2 - 3 } & Range & 3.0 \\
\hline \multirow{4}{*}{ Social work } & Mean & 27.2 \\
\cline { 2 - 3 } & Std. deviation & 3.8 \\
\cline { 2 - 3 } & Range & 14.0 \\
\hline \multirow{4}{*}{ Totacation } & Mean & 21.5 \\
\cline { 2 - 3 } & Std. deviation & 1.4 \\
\cline { 2 - 3 } & Range & 5.0 \\
\hline \multirow{4}{*}{} & Mean & 25.0 \\
\cline { 2 - 3 } & Std. deviation & 4.9 \\
\cline { 2 - 3 } & Range & 23.0 \\
\hline
\end{tabular}

performance and perceptions of professionalism, resilience, and reflective thinking were identified in the data. These six themes were an aggregate representation of 27 sub-themes, as depicted in Figure 1.

\section{Fieldwork - A window into the profession}

Unsurprisingly, many of the participants spoke extensively about the opportunities which fieldwork afforded them in exposing them to the lived experience of their profession of choice. They noted convergence and disparities between the theory of university courses and the "hands-on" reality of fieldwork, where eight subthemes were identified relating to bridging the university/ workplace divide (bridging the gap). Further, four subthemes were identified regarding becoming situated among other professionals and the keys to becoming a colleague (growing as a professional). Two additional sub-themes around the skills needed to cope with a 


\section{Relationships between fieldwork, professionalism, reflective-thinking and resilience}

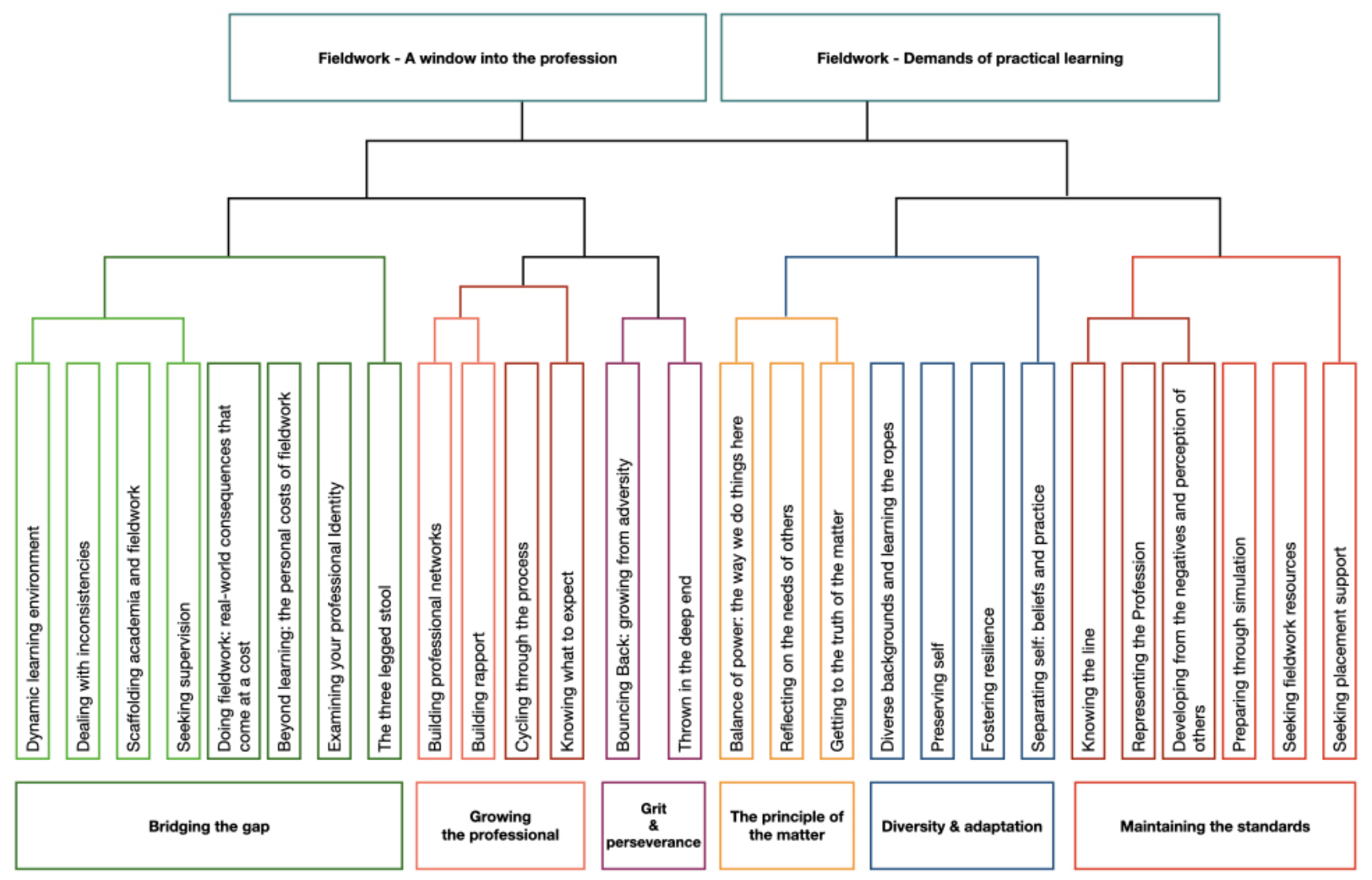

Figure 1: Themes and sub-themes dendrogram.

sudden transition from student to proto-professional (grit and perseverance) were identified. Each of these six themes is explored below.

\section{Theme 1: Bridging the gap}

This theme describes the interplay between university preparation for, and the realities of, fieldwork. It was coded into eight sub-themes (Figure 1). Fieldwork is seen by participants as a dynamic learning environment where skills and theories learned in the classroom began to make sense in a practical real-world way. For example, comparing university learning activities to fieldwork, an education student commented:

"It's really helpful for classroom management to say you can talk about how you're going to handle a student who's playing up, but it's very different to actually going out and doing it." (ED3; p. 11, 1. $10-12)$

Participants also found that fieldwork provided a level of practicality and a sense of consequence (e.g., client outcomes) that cannot be replicated in the classroom. This helped build future competence in less-tangible concepts such as forming therapeutic relationships or clinical reasoning skills. One pharmacy student revealed:

"It makes sense now, it's like tangible and you actually feel that like it's an actual patient rather than just having words on a screen." (PH3; p. 10, 1. 42-44)

Similarly, an OT student noted the stark contrast between the classroom and fieldwork:

"We did some mock interview in class, you can ask your partner to pretend being a client with a stroke, but it's really different from a real person with stroke with slow speech and so on. So that's a really important experience." (OT4; p. 12, 1. 34-36)

Participants indicated that fieldwork increased their ability to understand and apply non-technical skills to their practice, thus bridging the gap between controlled classroom environments and nuanced and unpredictable real-world experiences. Reflecting on the personal impact 
of placement, a pharmacy student stated:

"Without the context of having it in a real-world scenario with the real-world consequences as a result. Placements will be a good way to bridge that gap... it's a bit more personally impactful." (PH3; p. 20, 1. 9-12).

Participants noted an inconsistency between the concepts and practice recommendations learned at university and those experienced during fieldwork placements. As one SW student indicated: "I think a placement is our opportunity to learn how to deal with the conflicts between that ideal social work and the real social work" (SW1). Participants view these inconsistencies as pragmatic and functional choices based upon their supervisors' workload and resource availability in the field. Concerns were also noted regarding perceived inconsistent supervision, and sometimes contradictory advice. These experiences may result in mixed messages for students relating to best practice and the impact on assessments of their fieldwork competence. As one SW student reported:

"[They said] 'Yes, this is what you learn from your uni but in a practice, we don't do that.' And they just try to get me to accept that and to follow the requirements of the organisation rather than the theories." (SW1; p. 14, 1. 27-29)

Variability in the quantity and quality of supervisor guidance, feedback, and support was also perceived to impact participants' confidence in their decision-making during fieldwork. For example, an OT student linked developing confidence to having opportunities to act with independence:

"I think knowing that you can actually do something, depending on how much, what is the word, independence you were given in your setting can also influence whether that confidence grew or whether it actually went backwards." (OT3; p. 8, 1. 15-17)

Participants described a range of personal costs (e.g., loneliness, increased stress, and loss of income from part-time work) related to the practicalities of balancing university demands (e.g. assessments), fieldwork, and personal commitments. For instance, an education student commented: "...it's just hard to balance your academic commitments, as well as your placement commitments" (ED2), while an SW student stated: “it's just not fair to have a uni assignment while on placement as well as trying to have a life" (SW1).

Participants also noted the negative impact of late notification, changes to placement, and in some cases, the tyranny of distance from home to fieldwork venues. These could all compound financial hardship and loneliness. For instance, an OT student recalled:

"I got an email halfway through last week saying it's been cancelled. And you've been moved to Wodonga, which is four hours away. So I think that for me, I was like, 'All right, cool. What do I do now?'” (OT3; p. 13, 1. 19-21)

A second-year SW student also recounted:

"I've never been there [remote rural setting] before, so I think it's going to be a lifestyle and that's a part of the culture, and well it's very different from my own lifestyle so I think it's going to be a process... to just settle down." (SW2; p. 11, 1. 23-26)

There was a sense from participants that the difficulties they face during fieldwork play a significant role in developing the resilience needed to "bounce back." Fieldwork provided an opportunity to experience the complex balance of professionalism, resilience, honest reflective thinking, and the "passion" that their chosen profession demands. For instance, an education student commented:

"Yeah, it's kind of like a three-legged stool, and you're sitting on it, and you're in placement. If you're not professional, you're going to fall over. Or if you're not reflecting [on] all you've been doing, your class is going to fail, and you're going to fall over. If you're not resilient, first day, you're going to fall over. You can try and balance on two legs for a little bit, but really, particularly, you need all three to be really strong. Because otherwise, you'll fall over, and you won't be able to do it." (ED2; $p$. 21, 1. 27-33)

Participants also identified passion for their chosen profession as an important element for building resilience, with another education student stating:

“...one key factor is passion. If you don't have that passion for teaching, you're just going to collapse really quickly. No matter. That would not be any resilience. Then everything else is going to collapse." (ED3; p. 27, 1. 34-37)

\section{Theme 2: Growing as a professional}

Participants viewed fieldwork as a valuable exercise in enabling them to grow their own professional profiles, acquire knowledge of workplace culture and norms, and develop their interpersonal skills. They saw it as 
an opportunity to foster professional relationships, demonstrate competence, and to create "...a good first impression" (OT3; p. 6, 1. 22). Participants felt a need to prove their professional selves, as one third-year pharmacy student reflected:

"You realise that they are watching you in detail and they are noting how you conduct yourself around their workplace, not grooming you for a job...." (PH3; p. 19, 1. 11-13)

Many reported this was the first time they had encountered such scrutiny of their professional growth regarding interpersonal communication, building rapport, and developing their own practice styles and opinions. A second-year SW student described applying such skills in the clinical setting:

"...I had the ability to be a bit more informal because it was more about building a relationship with the child but also the parents. So, you would have to change the communication style depending on who you were talking to." (SW2; p. 2, 1. 20-22)

A third-year OT student reported that fieldwork was where they developed their identity as an OT, stating:

"It's [fieldwork] where you develop your professional identity. That's where you get that experience. Obviously, everyone's probably worked in other areas, but it's developing a professional identity within occupational therapy. That's where you do it." (OT3; p. 22, 1. 8-10)

Participants identified pre-fieldwork preparation as an area needing improvement. They felt relaying more anecdotes, tips, and common pitfalls would help them to visualize what to expect on fieldwork. While some felt "even just reading what others go through on their placement might help you better understand what you're in for" (OT3; p. 27, 1. 21-23) or these types of insights "...would give you insight into pitfalls" (OT3; p. 27, 1. 33 ), others realized that it may not be of much practical value:

"They can tell you these are the things that you are going to expect... you'll see that this might happen but then honestly, actual experience, you don't know how you are going to react. I think every placement is very different." (PH3; p. 27, 1. 34-37)

International students, in particular, flagged the benefits of workplace cultural acclimatization:

"If before we go to the field practice, we have some workshop and then we understand the difference of background of different organisations and what kind of service they are doing or even some social worker working there and share their experience in working at that organisation. About the culture, about the service, and their value. The thing that we can have broader understanding how social work in Australian contexts." (SW2; p. 15, 1. 23-28)

\section{Theme 3: Grit and perseverance}

Participants tended to view resilience in largely conventional terms as bouncing back from a difficult situation and continuing with their placement optimistically. Grit and perseverance were seen as a means to manage anxiety and distressing situations. As one education student commented:

"It's like when you get back in the car [at the end of the day], you sit there for a bit. Then you cry. Then you drive home, you go to bed. You get up the next morning, and then you go to work with a smile on your face. You just keep going." (ED2; p. 8, 1. 31-34)

Students also observed that perseverance had a selfprotective quality, as one pharmacy student explained:

"You need to be resilient too, not let that affect you as much. I know like you have to show empathy, you have to care for them. But then if you let that affect you, then I don't know, how would you be able to handle that every single day? That's so much emotional pressure on you and it's like that will affect your life every day and then you can't get back from that." (PH3; p. 7, 1. 38-41)

Reflection on practice also arose spontaneously and played a crucial and cyclical role as participants developed an understanding of what to expect from their experiences. As one OT student stated, "so I reflect like a lot. I did it every day in the shower - Shower thinking" (OT3; p. 31, 1. 16). While some participants viewed reflection as an “...ongoing process for you to improve yourself' (SW2; p. 5, 1. 27), other participants questioned more deeply where their insights into "what to expect" came from and how to include these reflections in their future practice. By bridging the gap between theory and practice, by exposing students to the realities of what it is like to be a professional in their career of choice, and by requiring the development of grit and perseverance, fieldwork acts as a window that gives students a preview of professional life. These practice-focused themes were complimented by others relating to the nature of fieldwork as a type of learning. We turn to these now. 


\section{Fieldwork - Demands of practical learning}

As a pedagogical method, fieldwork brings a unique set of challenges for students to deal with. Being in "live" workplaces and clinics introduces expectations and demands of students that are simply not present in a classroom. Fieldwork exposes students to local practices that are dictated by the host organization or mentor, typically with a strong focus on catering for the needs of clients. This often places students in difficult situations where they need to embrace a new world that is sometimes at odds with the world of the classroom (grouped under the theme: the principle of the matter). Similarly, they need to adapt to the diverse backgrounds of new colleagues and clients as they learn the ropes of the profession, while simultaneously bracketing their personal beliefs and views and discovering their professional identity and voice (theme: diversity and adaptation). As they start to identify with the profession, they become increasingly aware of having to represent the profession, and to use the criticism of others as a means of improving as a professional and adopting the practices of a professional in seeking their own resources, supports, and learning (theme: maintaining the standards). These three themes are explored in more detail below.

\section{Theme 4: The principle of the matter}

Participants were concerned about, but not surprised by, a perception of an uneven balance of power that they sometimes felt with supervisors or teachers. Participants accepted this imbalance with tolerant resignation and as an inconsequential relinquishment of their own principles for the sake of completing the placement. As one education student stated:

"But what I felt was, even though we're not happy about it [unconventional practice], because the power imbalance between supervisor and we don't like any trouble, so we just do what we have to do to pass the placement." (ED2; p. 10, 1. 25-27)

Participants were also mindful of their position of power over a patient, client, or child during fieldwork and felt the need to exert this power respectfully and carefully to the benefit of their client. An OT student commented, "you are in a position of power, so you use that power, if that's the right word. Just very respectfully. And carefully" (OT3; p. 3, 1. 3-4).

Conversely, participants also identified, and were often surprised by, the power that clients could bring to bear on fieldwork students. Participants reported professional growth arising from these encounters such as when interacting with a client who did not want to be treated by a student:

"It's a huge challenge of placement. But then at the same time, it is a benefit of placement because you learn how to manage clients like that, you learn how to manage that kind of interaction and how you're going to come back and develop your resilience around it and things like that." (OT4; p. 18, 1. 1-5)

Participants reported that professionalism was poorly defined and inconsistently role modeled by university faculty and fieldwork placement supervisors. One education student felt that the definition of professionalism is "very subjective, because they always say it's a professional manner, and you're like, 'What is that?" (ED2; p. 3,1.23-24), capturing a tension between students' own principles (e.g., providing patient-centered care over key performance indicators) and their understanding of what constitutes authentic professionalism (e.g., the core values of the profession).

\section{Theme 5: Diversity and adaptation}

Participants spoke of experiencing and adapting to a diverse set of cultures during fieldwork. These experiences were described as important and challenging elements, which sometimes entailed embracing difference, or required them to be simply accepted as different. Exposure to diverse communities, values, and cultures required students to adapt their own beliefs, principles, and behaviors. For example, one OT student commented:

"Sometimes you find that the things that you have to do in placement, the expectations and the professionalism of this profession is different from what your core beliefs are." (OT4; p. 18, 1. 27-28)

Adjustments ranged from superficial tweaking of behaviors to align with an agency's requirements (e.g. dress code), to intricate and weighty challenges to the participant's own beliefs and principles:

"With the acute hospital, they just want people in and out, and that can be a real challenge when you've got these different beliefs... but part of your professionalism is following that organisation's procedures and their vision on what their healthcare model is." (OT4; p. 19, 1. 4-6)

However, these tensions also promoted a view of resilience as an important and powerful part of participants' professional identity: 
"Resilience is, I guess acknowledging that there are differences and kind of just, not tolerating it, you just have to stand back up and make your professional identity known and disagree with, in a respectful and collaborative way, because otherwise you don't move forward, and you are just stuck in the same rut. And that is not resilience. That is just passiveness." (OT3; p. 5, 1. 26-30)

The tasks of adjusting, resisting, or balancing professional and personal beliefs were seen as a means of strengthening professional resilience. That is, a workplace culture could either encourage through supporting growth or, in an unsupportive and culturally unhealthy work environment, merely require students to develop their resilience as the means to cope. An SW student shared an example of the former:

"Something that comes to mind for me is the workplace culture, and if that can help foster individual resilience. So, having positive and supportive team and supervisors and a workplace that understands you as an individual in addition to the work that you do for the organisation, can help with resilience." (SW1; p. 6,1.13-16)

While an example of an unsupportive environment was given by an OT student:

"... it can be a power imbalance between management and staff, which says 'staff just have to become more resilient, go in a resilience course.' I have seen that happen too often and when in actual fact it is the culture of the workplace itself, whatever that workplace is, that can be toxic. And it is not up to staff to be resilient." (OT3; p. 5, 1. 14-18)

Fieldwork required students to adapt to diversity and made them aware of their role as advocates of cultural safety. They saw their own sensitivity to the cultural needs of their clients and colleagues as a key element of their professionalism:

"I think maybe you have kind of personal view about religion or maybe LGBTs or something like that. But a social worker, we really need to be very open minded and then basically see everyone as equal human beings." (SW2; p. 2, 1. 29-31)

However, some of the participants reported a lack of culturally sensitive reciprocity for their own cultural differences. For example, one first-year SW student described a situation where he was told he was "being not Asian enough, just because we decide to speak up for ourselves" (SW1; p. 15, 1. 40). Navigating these complexities of diversity and adaptation was seen as a central component of the fieldwork experience.

\section{Theme 6: Maintaining the standards}

There was a strong perception that following workplace guidelines and behaving in an ethically responsible way is a desirable professional trait, despite the potential for misalignment with one's own preferences or beliefs. For example, an OT student suggested that maintaining professionalism during fieldwork is recognized by patients and others in:

"How you dress, and how you... present yourself to the people who are around you, whether they be clients or within the multidisciplinary clinical team, it's how you dress, how you have your badge, how you have your hair, all those considerations all fall under that umbrella." (OT4; p. 3, 1. 15-18)

Participants also indicated that treating client data as confidential was an important element in ensuring the trustworthiness of individual students and their professional discipline. While some participants perceived this as following guidelines, others described ethical professional behavior as a value that transcended organizational requirements. One pharmacy student observed:

"...I think a big part of professionalism in our profession at least, is privacy. And pharmacists are one of the most trusted professionals. And when people come in, we need to show that we respect them, we hear them, but also that their business is staying their business. There's a lot of stuff that we come in contact to that, if it got out there, it would really upset people. They would lose trust in that particular pharmacy. I feel like, when we're going on placements, we have to make sure that we're upholding those privacy rules and laws and guidelines." (PH4; p. 3, 1. 12-17)

This suggests that participants consider professionalism as being expressed in terms of presentation through dress, communication, and ethical, respectful practice. This complimented views around reputation - both theirs and the profession's - which often manifested in reflections on negative aspects of their performance (i.e., what went wrong). This was evident by the inward-looking critique of a third-year pharmacy student who shared that " $I$ ' $m$ someone that's pretty critical of myself, so there's always something I feel like I need to improve on" (PH3; p. 5, $12-3)$. However, such reflective practices could also be 
outward seeking, for instance, being open to the views of others, as expressed by a third-year OT student:

"Sometimes we're hard on ourselves and we focus on the things we did wrong and not the things we did right. So that's part of reflective thinking as well. And getting feedback from other people as well, because sometimes the things that you see from your perspective wasn't how other people saw what went on too. So that's important." (OT3; p. 4, 1 11-14)

Participants desired practical tools such as fieldwork handbooks and learning management system modifications to use, not only during fieldwork, but also as an aide-mémoire as they transitioned to the workforce. As a second-year education student said:

“... a handbook that you can use, it's like a bible for what you should do in placement and that kind of stuff, and how to manage possibly would really help. Something you can use throughout the university life, and then potentially even continue when you become a teacher." (ED2; p. 26, 121-24)

Participants also sought easy access to expert and targeted feedback from on-site supervisors, which they perceived as rare, or as one student stated, "They're like unicorns" (ED2). A level of assertiveness was required of students to gain feedback:

"Sometimes if I want to get help, get direction for where I'm going to improve, I had to actually seek out one of my tutors and it would be nice if it was just forthcoming" (OT3; p. 28, 1 11-13)

and

“... it was just kind of like, 'I'm here. Here's my card, if you need anything, talk to me, or there's also a teacher here that manages people.' Then it's like I don't want to bother you. I don't know if this is ok to talk to you about." (ED2; p. 25, 1 14-17)

Supportive individuals and services, other than the supervisor, were also mentioned as resources for learning. For example, participants were eager for mentoring and insights from near peers:

"Maybe you can talk to the person who did a similar placement as you last year or last semester. Should they, he or she, share much experience with you, that would be very helpful." (SW2; p. 14, 1 15-17)
Greater pastoral care from universities was further seen to be an area of support that participants believed could improve the standard of their preparation for, and performance during, fieldwork:

"It would be good if [university supervisors] checked in with you before you started placement, as well. Rather than just in the middle of placement or at the end of placement. Sometimes just the anxiety of going on placement can be really, really tough. Especially that first day." (ED2; p. 23, 1 1-4)

\section{DISCUSSION}

This study examined the relationship between university students' fieldwork participation and their perceptions of professionalism, resilience, and reflective thinking. Participants' perceived professionalism not only in broadly conventional terms (e.g., as a commitment to, and in concordance with, ethical practice), but also as a deeper examination of how their own behaviors, beliefs, and attitudes impact their patients or pupils.

Participants emphasized the importance of reflecting on their own beliefs and attitudes in relation to the rights of patients or clients, which aligns with one of the key domains in the Charter on Professionalism for Health Care Organizations (Egener et al., 2017). The Charter describes the importance of patient- and family-centered professional practice, which provides those being cared for with respect for their partnership, values, beliefs, and needs. The findings of this study also reveal that undergraduate and graduate-entry master's OT, pharmacy, SW, and education students appear to embrace self-evaluation and believe it equips them well for future practice.

The "caring professions" are often situated in stressful and personally demanding environments where having to meet the needs of patients and clients can overshadow the needs of the care provider (Salyers et al., 2017). While developing resilience was reported by participants as a challenging but necessary characteristic for professional survival, there was also evidence that they felt inadequately supported in their efforts to do so. These data also confirm previous research highlighting an unacceptable gap between ideal workplace cultures and those in which health-care workers (Yassi \& Hancock, 2005) and teachers (Klassen et al., 2018) currently practice. This gap can lead to serious negative outcomes for practitioners, workforce retention, and the quality of care (Cleary, Kornhaber, Thapa, West, \& Visentin, 2018). Participants described their strategies for developing competence as a balance of academic preparation and support from the university and fieldwork site, as well 
as their own reflective thinking practices. However, the data indicate that participants relied more on their own critical reflection than any simulations or preparation they received in the classroom. This finding provides further evidence of the need for greater support and guidance around building coping skills (Hickson, Williams, \& O’Meara, 2015).

In this study, participants reported that professionalism reflected the broader discipline's reputation and their own competence, trustworthiness, and employability. While there was evidence that participants strove for professionalism, they also had concerns about a lack of any clear definition of professionalism, or at least inconsistent definitions. This is an important finding in light of literature which, for more than a decade, has advocated for reliance upon well-defined and measurable professional outcomes instead of abstract principlesbased professionalism preparation (Lesser et al., 2010).

The findings from this study reveal that bridging the gap between the theoretical underpinnings of practice and the real-world placement experience is perceived by participants as an important element of fieldwork which has practical, fiscal, and social consequences. Geographic and structural barriers related to fieldwork can also reduce the ability of participants to benefit fully from the experience. Similar barriers have been described elsewhere (Alshahrani, Cusack, \& Rasmussen, 2018; Cuervo \& Acquaro, 2018; White \& Humphreys, 2014). Such challenges can impact the motivation of students to complete, or how satisfied they feel with, a fieldwork practicum and highlights an area requiring further research, particularly given such disaccord can erode the confidence of a student in their own profession and its ideals (Jonsén, Melender, \& Hilli, 2013; Saifan, AbuRuz, \& Masa'deh, 2015; White \& Humphreys, 2014). Though far from a new recommendation (Roth, Mavin, \& Dekker, 2014), collaborative efforts to align pre-registration training and real-world practice are a key priority for accreditation and registration bodies, university course advisory committees, industry (health and education) policy makers, and educational researchers.

Participants further reported a lack of support staff availability and resources while they were on placement and indicated this resulted in them creating their own mental models based on a complex balance of professionalism, resilience, and honest reflective thinking. While it has been reported that this type of self-reliance may be an important element to building resilience (Hickson et al., 2015), providing additional supports, guided reflective practice, resilience-building interventions (Vaughan, Stoliker, \& Anderson, 2020), near-peer mentoring, and shared experience could increase the abilities of students to focus their energies more productively during fieldwork.

\section{LIMITATIONS}

There are several limitations to this study related to its design and analysis. The study was limited to a single university, and therefore, generalizability of the findings to other tertiary settings may be difficult. There is, however, sufficient description of the setting, participants, and the fieldwork requirements to provide enough context to generalize the findings to other working environments. The heterogeneity of the participant groups may also have had an effect on the findings presented. For example, there were nearly twice as many participants with international enrollment status than those with domestic enrollment status.

There is also a risk that an outspoken participant could dominate or significantly drive the flow of the focus group conversation. The expertise of the moderator was such that this risk was minimized.

The data analysis process also identified issues related to the design of the focus group schedule (questions and prompts). The authors suggest that greater qualitative rigor during the planning stage may have resulted in better understanding of student reflective practices and how these might impact on future workforce issues (e.g., willingness to stay in the profession).

The volume of qualitative data from focus groups can also present a risk for misinterpretation of the data. However, data were analyzed by two authors with experience and expertise to mitigate risk of misinterpretation. All coding, themes, and sub-themes were discussed and moderated to ensure inter-coder agreement in terms of relevance and meaning.

\section{FUTURE RESEARCH}

The outcomes from this study indicate a need for collaborative (academic and industry) studies that investigate key theory-practice gaps for OT, pharmacy, SW, and education and ways in which the frequency and risk of these gaps can be mitigated. Further investigation of the concepts of professionalism, resilience, reflective thinking, and students' fieldwork involvement using a mixed-methods approach is recommended to broaden the base of the findings of this study.

\section{IMPLICATIONS AND RECOMMENDATIONS}

The findings of this study highlight the personal, financial, and geographic impacts of fieldwork on participants and clearly show the role of universities to provide students with sufficient time to prepare for fieldwork, particularly for those allocated to a geographic location that would require them to move away from their primary place of residence. 
Pre-fieldwork preparation should include mechanisms for matching students with near peers who have completed fieldwork in the same, or a similar, venue. This may help students prepare for the fieldwork environment with an awareness of context and facilitate workplace cultural acclimatization.

Finally, fieldwork preparation would benefit from embedding practical skill development related to professionalism, reflective thinking, and resilience within the course curriculum. These three factors represent the three-legged stool of fieldwork.

\section{CONCLUSION}

The interplay between university students' perceptions of professionalism, resilience, and reflective thinking is inextricably linked with self-reported fieldwork performance. Students who are required to complete fieldwork are independently able to build mental models of professionalism, resilience, and reflective thinking, which support their performance. However, these mental models should be underpinned by theory and further supports should be provided in undergraduate curricula to assist with this process. University and industry concordance related to theory-practice gaps is long overdue to support students' confidence in developing their own identities in their chosen professions.

\section{FUNDING}

This study was funded in part by the Faculty of Medicine, Nursing \& Health Sciences Learning \& Teaching Research Grant Scheme 2019, Monash University, Clayton, Victoria, Australia.

\section{ACKNOWLEDGMENT}

The authors would like to acknowledge the time and thoughtful input provided by the participants for the study. This research would not have been possible without their candor, honest reflection, and commitment to informing the aims of the study.

\section{ETHICAL APPROVAL}

University Human Research Ethics Committee approval was obtained in January 2019 (Project ID: 15205).

\section{CONFLICTS OF INTEREST}

The authors have no conflicts of interest to report.

\section{References}

Alshahrani, Y., Cusack, L., \& Rasmussen, P. (2018). Undergraduate nursing students' strategies for coping with their first clinical placement: Descriptive survey study. Nurse Education Today, 69, 104-108. doi:10.1016/j.nedt.2018.07.005

Argyris, C. (1991). Teaching smart people how to learn. Harvard Business Review, 69(3).

Arnold, L. (2002). Assessing professional behavior: yesterday, today, and tomorrow. Academic Medicine, 77(6), 502-515. doi:10.1097/00001888-200206000-00006

Australian Association of Social Workers. (2015). Practice Standards. Retrieved from https:/www.aasw.asn.au/document/item/4551

Australian Institute for Teaching and School Leadership. (2018). Australian Professional Standards for Teachers. Retrieved from https://www.aitsl.edu.au/docs/default-source/national-policyframework/australian-professional-standards-for-teachers.pdf

Australian Pharmacy Council. (2020). Accreditation Standards for Pharmacy Programs. Retrieved from https://www. pharmacycouncil.org.au/resources/pharmacy-program-standards/

Barnard, D. (2016). Vulnerability and Trustworthiness Polestars of Professionalism in Healthcare. Cambridge Q. Healthcare Ethics, $25,288$.

Bonello, M. (2016). Fieldwork within the context of higher education: a literature review. British Journal of Occupational Therapy, 64(2), 93-99. doi:10.1177/030802260106400207
Braun, V., \& Clarke, V. (2006). Using thematic analysis in psychology. Qualitative research in psychology, 3(2), 77-101.

Brown, T., Yu, M. L., Hewitt, A., \& Etherington, J. (2020). Professionalism as a predictor of fieldwork performance in undergraduate occupational therapy students: an exploratory study. Occupational Therapy in Health Care, 34(2), 131-154. doi:10.1080 /07380577.2020.1737896

Brown, T., Yu, M. L., Hewitt, A. E., Isbel, S. T., Bevitt, T., \& Etherington, J. (2020). Exploring the relationship between resilience and practice education placement success in occupational therapy students. Australian Occupational Therapy Journal, 67(1), 49-61.

Cleary, M., Kornhaber, R., Thapa, D. K., West, S., \& Visentin, D. (2018). The effectiveness of interventions to improve resilience among health professionals: A systematic review. Nurse Education Today, 71, 247-263. doi:10.1016/j.nedt.2018.10.002

Cuervo, H., \& Acquaro, D. (2018). Exploring metropolitan university pre-service teacher motivations and barriers to teaching in rural schools. Asia-Pacific Journal of Teacher Education, 46(4), 384398. doi:10.1080/1359866x.2018.1438586

Dewey, J. (1997). How we think: Courier Corporation.

Egener, B. E., Mason, D. J., McDonald, W. J., Okun, S., Gaines, M. E., Fleming, D. A., . . . Andresen, M. L. (2017). The charter on professionalism for health care organizations. Academic Medicine, 92(8), 1091-1099. doi:10.1097/ACM.0000000000001561 
Fairbrother, M., Nicole, M., Blackford, J., Nagarajan, S. V., \& McAllister, L. (2016). A new model of clinical education to increase student placement availability: The Capacity Development Facilitator Model. Asia-Pacific Journal of Cooperative Education, 17(1), 45-59.

Henrich, N. J., Dodek, P. M., Gladstone, E., Alden, L., Keenan, S. P., Reynolds, S., \& Rodney, P. (2017). Consequences of moral distress in the intensive care unit: a qualitative study. American Journal of Critical Care, 26(4), e48-e57. doi:10.4037/ajcc2017786

Hickson, H., Williams, B., \& O’Meara, P. (2015). Paramedicine students' perception of preparedness for clinical placement in Australia and New Zealand. BMC Medical Education, 15(1), 168. doi:10.1186/s12909-015-0446-7

Jonsén, E., Melender, H.-L., \& Hilli, Y. (2013). Finnish and Swedish nursing students' experiences of their first clinical practice placement: A qualitative study. Nurse Education Today, 33(3), 297-302.

Joseph, D., \& Rouse, E. (2017). International students experience in teacher education: Creating context through play workshops. Australian Journal of Teacher Education, 42(9), 3.

Klassen, R. M., Durksen, T. L., Al Hashmi, W., Kim, L. E., Longden, K., Metsäpelto, R.-L., . . Györi, J. G. (2018). National context and teacher characteristics: Exploring the critical non-cognitive attributes of novice teachers in four countries. Teaching and Teacher Education, 72, 64-74. doi:10.1016/j.tate.2018.03.001

Lalor, A., Yu, M.-L., Brown, T., \& Thyer, L. (2019). Occupational therapy international undergraduate students' perspectives on the purpose of practice education and what contributes to successful practice learning experiences. British Journal of Occupational Therapy, 82(6), 367-375. doi:10.1177/0308022618823659

Larson, M. S. (2014). Looking back and a little forward: Reflections on professionalism and teaching as a profession. Radical Teacher, 99, 7-18.

Lesser, C. S., Lucey, C. R., Egener, B., Braddock, C. H., 3rd, Linas, S. L., \& Levinson, W. (2010). A behavioral and systems view of professionalism. JAMA, 304(24), 2732-2737. doi:10.1001/ jama.2010.1864

Lopez, V., Yobas, P., Chow, Y. L., \& Shorey, S. (2018). Does building resilience in undergraduate nursing students happen through clinical placements? A qualitative study. Nurse Education Today, 67, 1-5. doi:10.1016/j.nedt.2018.04.020

Maloney, S., Tai, J. H., Lo, K., Molloy, E., \& Ilic, D. (2013). Honesty in critically reflective essays: an analysis of student practice. Advances in Health Science Education: Theory and Practice, 18(4), 617-626. doi:10.1007/s10459-012-9399-3

Mann, K., Gordon, J., \& MacLeod, A. (2009). Reflection and reflective practice in health professions education: a systematic review. Advances in Health Science Education: Theory and Practice, 14(4), 595-621. doi:10.1007/s10459-007-9090-2

McAllister, L., \& Nagarajan, S. V. (2015). Accreditation requirements in allied health education: strengths, weaknesses and missed opportunities. Journal of Teaching and Learning for Graduate Employability, 6(1), 2-24.
Medical Professionalism Project. (2002). Medical professionalism in the new millennium: a physicians' charter. The Lancet, 359(9305), 520-522. doi:10.1016/s0140-6736(02)07684-5

Melman, S., Ashby, S. E., \& James, C. (2016). Supervision in practice education and transition to practice: student and new graduate perceptions. Internet Journal of Allied Health Sciences and Practice, 14(3), 1.

Occupational Therapy Board of Australia. (2018). Australian occupational therapy competency standards. Retrieved from https://www.occupationaltherapyboard.gov.au/codes-guidelines/ competencies.aspx

Rakesh, G., Pier, K., \& Costales, T. L. (2017). A call for action: Cultivating resilience in healthcare providers. American Journal of Psychiatry Residents' Journal, 12(4), 3-5. https://doi.org/10.1176/ appi.ajp-rj.2017.120402

Redmond, R., \& Curtis, E. (2009). Focus groups: principles and process. Nurse Researcher, 16(3), 57-69. doi:10.7748/nr2009.04.16.3.57. c6946

Roth, W.-M., Mavin, T., \& Dekker, S. (2014). The theory-practice gap: epistemology, identity, and education. Education + Training, 56(6), 521-536. https://doi.org/10.1108/ET-11-2012-0117

Russo, S. J., Murrough, J. W., Han, M. H., Charney, D. S., \& Nestler, E. J. (2012). Neurobiology of resilience. Nature Neuroscience, 15(11), 1475-1484. doi:10.1038/nn.3234

Saifan, A., AbuRuz, M. E., \& Masa'deh, R. (2015). Theory practice gaps in nursing education: a qualitative perspective. Journal of Social Sciences, 11(1), 20-29. DOI:10.3844/jssp.2015.20.29

Salyers, M. P., Bonfils, K. A., Luther, L., Firmin, R. L., White, D. A., Adams, E. L., \& Rollins, A. L. (2017). The Relationship Between Professional Burnout and Quality and Safety in Healthcare: A Meta-Analysis. Journal of General Internal Medicine, 32(4), 475482. doi:10.1007/s11606-016-3886-9

Schön, D. (1938). The reflective practitioner. New York, 1083.

van Vuuren, E. C. J., Bodenstein, K., \& Nel, M. (2018). Stressors and coping strategies among physiotherapy students: Towards an integrated support structure. Health SA Gesondheid, 23(1).

Vaughan, A. D., Stoliker, B. E., \& Anderson, G. S. (2020). Building personal resilience in primary care paramedic students, and subsequent skill decay. Australasian Journal of Paramedicine, 17. doi:10.33151/ajp.17.803

Venegas, C. L., Nkangu, M. N., Duffy, M. C., Fergusson, D. A., \& Spilg, E. G. (2019). Interventions to improve resilience in physicians who have completed training: A systematic review. PloS One, 14(1), $\mathrm{e} 0210512$.

White, S., \& Humphreys, N. (2014). Undergraduate physiotherapy students' expectations and perceptions of rural/regional clinical placements. Australian Journal of Rural Health, 22(4), 172-178. doi:10.1111/ajr.12102

Yassi, A., \& Hancock, T. (2005). Patient safety-worker safety: building a culture of safety to improve healthcare worker and patient wellbeing. Healthc $Q, 8(32), 8$. 